\title{
Kawasaki-like Syndrome as an Emerging Complication of SARS-CoV-2 Infection in Young Adults
}

\author{
César Burgi Vieira ${ }^{1}$, Ana Teresa Ferreira² ${ }^{2}$ Filipa Botelho Cardoso ${ }^{3}$, Jorge Pelicano Paulos ${ }^{4}$, Nuno Germano ${ }^{5}$ \\ ${ }^{1}$ Unidade Funcional Medicina 2.4, Centro Hospitalar Universitário de Lisboa Central, Lisboa, Portugal \\ ${ }^{2}$ Unidade Funcional Medicina 4, Centro Hospitalar Universitário de Lisboa Central, Lisboa, Portugal \\ ${ }^{3}$ Unidade Funcional Medicina 1.4, Centro Hospitalar Universitário de Lisboa Central, Lisboa, Portugal \\ ${ }^{4}$ Departamento de Anestesiologia, Centro Hospitalar Universitário de Lisboa Central, Lisboa, Portugal \\ ${ }_{5}^{5}$ Unidade de Cuidados Intensivos Polivalente 7, Centro Hospitalar Universitário de Lisboa Central, Lisboa, Portugal
}

\begin{abstract}
Received: $14 / 07 / 2020$
Accepted: $19 / 07 / 2020$
\end{abstract}

Published: $10 / 09 / 2020$

How to cite this article: Burgi Vieira C, Ferreira AT, Botelho Cardoso F, Pelicano Paulos J, Germano N. Kawasaki-like syndrome as an emerging complication of SARS-CoV-2 infection in young adults. EJCRIM 2020;7: doi:10.12890/2020_001886.

Acknowledgements: All authors contributed equally to the manuscript.

Conflicts of Interests: The Authors declare that there are no competing interests.

This article is licensed under a Commons Attribution Non-Commercial 4.0 License

\section{ABSTRACT}

Background: Kawasaki-like syndrome occurring in children during the COVID-19 pandemic has been labelled multisystem inflammatory syndrome in children (MIS-C) by the CDC and paediatric inflammatory multisystem syndrome temporally associated with SARS-CoV-2 infection (PIMS-TS) by the ECDC.

Case report: We report the case of an 18-year-old male patient presenting with a 72-hour history of abdominal pain, fever, erythematous skin rash, vomiting and diarrhoea. Examination showed he also had shock and he was first thought to have oedematous cholecystitis. SARS-CoV-2 infection was also diagnosed. He was admitted to the ICU, and echocardiography showed cardiac dysfunction, with a low ejection fraction and low cardiac index. High-sensitivity troponin serum levels were elevated. The patient received inotropic and vasopressor support. As he fulfilled several criteria for MIS-C/PIMS-TS, he was administered acetylsalicylic acid, corticosteroids and immunoglobulin, with a good clinical response.

Conclusion: This case emphasizes how this severe presentation of COVID-19 can easily be misdiagnosed if the clinician is less aware of this syndrome in younger patients.

\section{LEARNING POINTS}

- SARS-CoV-2 infection is a diagnostic challenge in some patients with atypical clinical presentations, who may have MIS-C/PIMS-TS.

- Physicians should be aware of this condition when evaluating teenagers and young adults with COVID-19.

\section{KEYWORDS}

COVID-19, Kawasaki syndrome, vasculitis, adult, multisystem inflammatory syndrome

\section{INTRODUCTION}

Severe acute respiratory syndrome coronavirus 2 (SARS-CoV-2) infection in younger patients is usually associated with absent or mild respiratory symptoms in contrast to the severe forms described in adults ${ }^{[1]}$. Moreover, an association between SARS-CoV-2 disease 2019 
(COVID-19) and a hyperinflammatory response mimicking vasculitis has been increasingly considered possible, particularly in this age group, and presumed to be a post-viral reaction ${ }^{[1]}$.

Albeit rare, Kawasaki disease is the most common systemic acute vasculitis in children and coronary aneurysms are its most severe complication. Its cause is still unknown although a temporal link with some viral infections has been suggested ${ }^{[2]}$. Diagnosis is clinical and established by prolonged fever, exanthema or rash with desquamation, conjunctival injection, neck lymphadenopathy and oral mucosal changes such as cheilitis, glossitis and pharyngitis ${ }^{[3]}$.

Several clusters of children with Kawasaki-like syndrome have been reported during the ongoing COVID-19 pandemic ${ }^{[4]}$ and this presentation has been labelled multisystem inflammatory syndrome in children (MIS-C) by the $\mathrm{CDC}^{[5]}$ and paediatric inflammatory multisystem syndrome temporally associated with SARS-CoV-2 infection (PIMS-TS) by the ECDC [6].

\section{CASE DESCRIPTION}

We report the case of a previously healthy 18-year-old male patient who was admitted to our intensive care unit (ICU). He initially presented to the emergency department with abdominal pain, fever, vomiting and diarrhoea for 72 hours. Examination revealed severe hypotension $(63 / 31 \mathrm{mmHg})$, thrombocytopenia $\left(61 \times 10^{\%} / \mathrm{l}\right)$, increased C-reactive protein $(310 \mathrm{mg} / \mathrm{l})$, acute kidney injury (serum creatinine $\left.3.31 \mathrm{mg} / \mathrm{dl}\right)$ and hyperlactatemia ( $6.2 \mathrm{mmol} / \mathrm{l})$. An abdominal CT scan only revealed minor gallbladder distension. Exploratory laparotomy revealed alithiasic oedematous cholecystitis and an uneventful cholecystectomy was performed. Due to the ongoing COVID-19 pandemic, all surgical patients must also have a SARS-CoV-2 PCR test on a nasopharyngeal swab. As the result was positive and shock criteria were still present, the patient was transferred to our ICU for post-operative care.

Upon arrival, the patient was mechanically ventilated and under circulatory support with norepinephrine $0.5 \mu \mathrm{g} / \mathrm{kg} / \mathrm{min}$ to maintain a mean blood pressure above $65 \mathrm{mmHg}$. Clinically, the skin was mottled, capillary reperfusion time was prolonged and serum lactate remained high (3.2 mmol/l). Fluid resuscitation with $30 \mathrm{ml} / \mathrm{kg}$ of crystalloids had limited effect, and so echocardiography was performed to assess heart function and volume status. Echocardiography showed enlarged cavities (Fig. 1), mitral regurgitation due to mitral ring dilation (Fig. 2), a low ejection fraction (35\%) and a low cardiac index $\left(2.2 \mathrm{l} / \mathrm{min} / \mathrm{m}^{2}\right)$ as well as an enlarged inferior vena cava (Figs. 1 and 2).

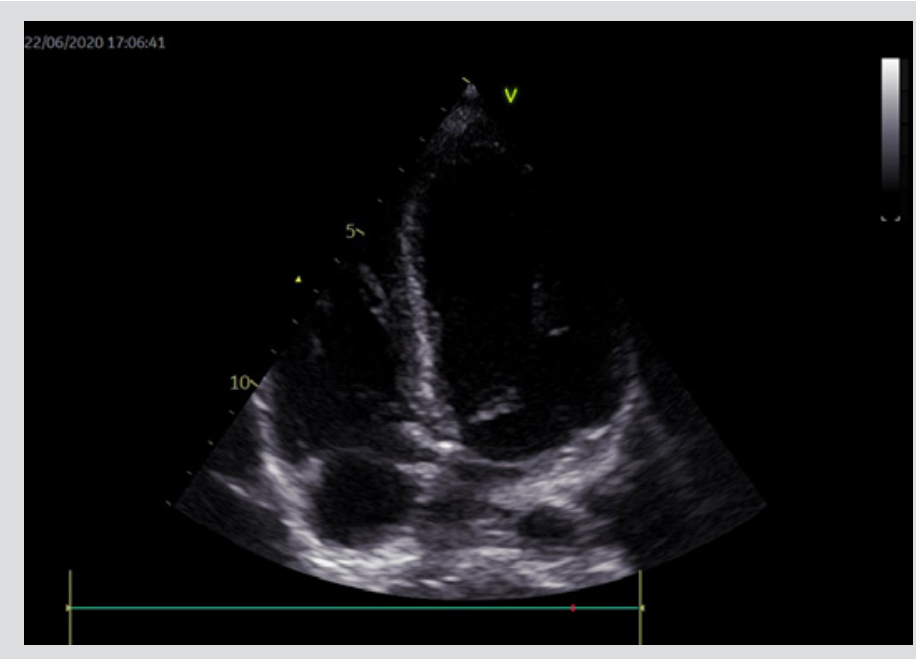

Figure 1. Cardiac cavity enlargement shown by transthoracic echocardiography

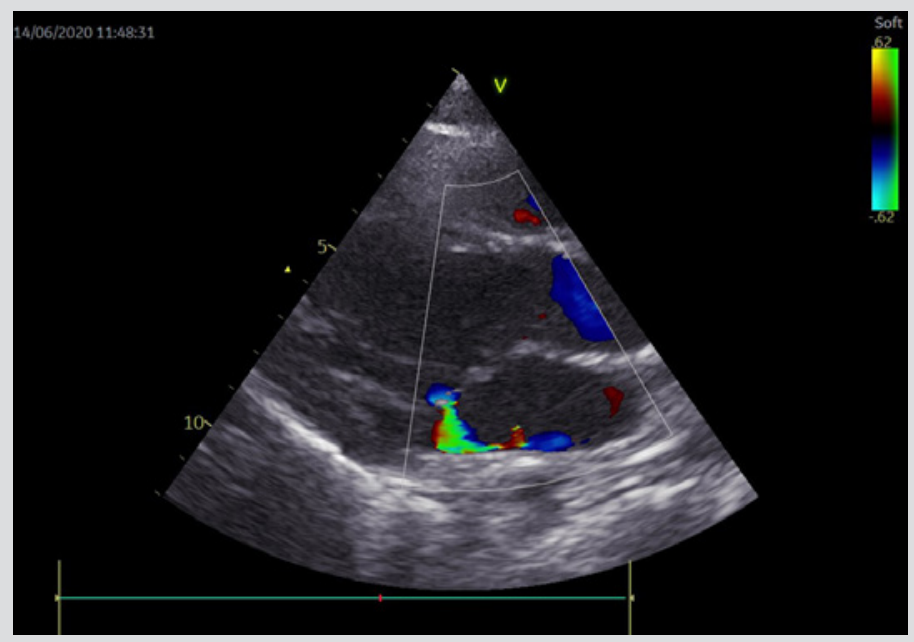

Figure 2. Mitral regurgitation

Transpulmonary thermodilution monitoring was also set up and showed a low cardiac index, low systemic vascular resistance index, elevated global end-diastolic volume index and elevated extravascular lung water index. Inotropic support was started and dobutamine was initially titrated to $7.5 \mu \mathrm{g} / \mathrm{kg} / \mathrm{min}$.

Laboratory work-up showed that all inflammatory markers increased steeply during the first 24 hours: C-reactive protein was 260.9 mg/l, procalcitonin $33.5 \mathrm{ng} / \mathrm{ml}$, IL-6 $1119 \mathrm{pg} / \mathrm{ml}$ and ferritin 4,260.5 ng/ml. Furthermore, high sensitivity troponin I and D-dimer levels also rose to $963.2 \mathrm{pg} / \mathrm{ml}$ and 9,225 $\mu \mathrm{g} / \mathrm{l}$, respectively (Table 1).

Following detailed analysis of the clinical course and a careful physical examination, we concluded that the patient fulfilled some of the CDC criteria for MIS-C, as well as the ECDC criteria for PIMS-TS: age under 21 years, fever above $38^{\circ} \mathrm{C}$ for over 24 hours, abdominal pain, erythematous skin rash, conjunctival injection, myocarditis with cardiogenic shock, distributive shock and elevated inflammatory parameters (Table 2). 
- An individual aged <21 years presenting with fever, laboratory evidence of inflammation, and evidence of clinically severe illness requiring hospitalization, with multisystem (>2) organ involvement (cardiac, renal, respiratory, haematological, gastrointestinal, dermatological or neurological) AND

- Positive for current or recent SARS-CoV-2 infection by RT-PCR, serology or antigen test; or COVID-19 exposure within the 4 weeks prior to the onset of symptoms AND

- No alternative plausible diagnoses

Preliminary UK case definition for paediatric inflammatory multisystem syndrome temporally associated with SARS-CoV-2 infection (PIMS-TS)

- A child presenting with persistent fever, inflammation (neutrophilia, elevated CRP and lymphopaenia) and evidence of single or multi-organ dysfunction (shock, cardiac, respiratory, renal, gastrointestinal or neurological disorder) with other additional clinical, laboratory or imagining and ECG features. Children fulfilling full or partial criteria for Kawasaki disease may be included

- Exclusion of any other microbial cause, including bacterial sepsis, staphylococcal or streptococcal shock syndromes, infections associated with myocarditis such as enterovirus;

- SARS-CoV-2 PCR testing positive or negative

Table 1. Current definitions for MIS-C and PIMS-TS. Sources: emergency.cdc.gov and ecdc.europa.eu

\begin{tabular}{|c|c|c|c|c|c|}
\hline & $\begin{array}{c}\text { Day } 1 \\
\text { (ICU admission) }\end{array}$ & $\begin{array}{c}\text { Day } 1 \\
\text { (12h after admission) }\end{array}$ & Day 2 & Day 3 & Day 5 \\
\hline Haemoglobin & $12.3 \mathrm{~g} / \mathrm{dl}$ & $12.8 \mathrm{~g} / \mathrm{dl}$ & $10.9 \mathrm{~g} / \mathrm{dl}$ & $9.7 \mathrm{~g} / \mathrm{dl}$ & $9.7 \mathrm{~g} / \mathrm{dl}$ \\
\hline Haematocrit & $36.9 \%$ & $38.6 \%$ & $32.3 \%$ & $28.2 \%$ & $28.9 \%$ \\
\hline Leukocytes & $17,840 \times 10^{9} / /$ & $17,320 \times 10^{9} / /$ & $28,050 \times 10^{9} / 1$ & $24,050 \times 10^{9} / 1$ & $15,410 \times 10^{9} / I$ \\
\hline Neutrophils & $16,420 \times 10^{9} /$ I (92\%) & $16,320 \times 10^{9} /(94.2 \%)$ & $27,160 \times 10^{9} / /(96.9 \%)$ & $21,570 \times 10^{9} / /(89.7 \%)$ & $13,530 \times 10^{9} / 1(87.8 \%)$ \\
\hline Lymphocytes & $920 \times 10^{9} / /(5.2 \%)$ & $520 \times 10^{9} / 1(3 \%)$ & $400 \times 10^{9} / /(1.4 \%)$ & $2,100 \times 10^{9} / /(8.7 \%)$ & $1,530 \times 10^{9} / I(9.9 \%)$ \\
\hline Platelets & $107 \times 10^{9} / /$ & $77 \times 10^{9} / 1$ & $85 \times 10^{9} / 1$ & $85 \times 10^{9} / 1$ & $122 \times 10^{9} / /$ \\
\hline INR & 1.46 & 1.38 & 1.32 & 1.29 & 1.20 \\
\hline Creatinine & $1.74 \mathrm{mg} / \mathrm{dl}$ & $1.18 \mathrm{mg} / \mathrm{dl}$ & $1.03 \mathrm{mg} / \mathrm{dl}$ & $1.12 \mathrm{mg} / \mathrm{dl}$ & $0.82 \mathrm{mg} / \mathrm{dl}$ \\
\hline Total bilirubin & $0.99 \mathrm{mg} / \mathrm{dl}$ & $1.11 \mathrm{mg} / \mathrm{dl}$ & $0.69 \mathrm{mg} / \mathrm{dl}$ & $0.50 \mathrm{mg} / \mathrm{dl}$ & $0.42 \mathrm{mg} / \mathrm{dl}$ \\
\hline AST/GOT & $117 \mathrm{U} / \mathrm{I}$ & $112 \mathrm{U} / \mathrm{I}$ & $103 \mathrm{U} / \mathrm{I}$ & $72 \mathrm{U} / \mathrm{I}$ & $82 \mathrm{U} / \mathrm{I}$ \\
\hline ALT/GPT & $64 \mathrm{U} / \mathrm{I}$ & $72 \mathrm{U} / \mathrm{I}$ & $74 \mathrm{U} / \mathrm{I}$ & $60 \mathrm{U} / \mathrm{I}$ & $61 \mathrm{U} / \mathrm{I}$ \\
\hline C-reactive protein (CRP) & $276 \mathrm{mg} / \mathrm{l}$ & $269 \mathrm{mg} / \mathrm{l}$ & $260.9 \mathrm{mg} / \mathrm{l}$ & $276 \mathrm{mg} / \mathrm{l}$ & $159.9 \mathrm{mg} / \mathrm{l}$ \\
\hline $\begin{array}{c}\text { Troponin I } \\
\text { (high sensitivity) }\end{array}$ & $977 \mathrm{pg} / \mathrm{ml}$ & $791 \mathrm{pg} / \mathrm{ml}$ & $963.2 \mathrm{pg} / \mathrm{ml}$ & $746 \mathrm{pg} / \mathrm{ml}$ & $477.9 \mathrm{pg} / \mathrm{ml}$ \\
\hline Ferritin & $3,140 \mathrm{ng} / \mathrm{ml}$ & $4,387 \mathrm{ng} / \mathrm{ml}$ & $4,260.5 \mathrm{ng} / \mathrm{ml}$ & $2,869 \mathrm{ng} / \mathrm{ml}$ & \\
\hline Procalcitonin & $78 \mathrm{ng} / \mathrm{ml}$ & $53.65 \mathrm{ng} / \mathrm{ml}$ & $33.50 \mathrm{ng} / \mathrm{ml}$ & $20.56 \mathrm{ng} / \mathrm{ml}$ & $7.18 \mathrm{ng} / \mathrm{ml}$ \\
\hline
\end{tabular}

Table 2. The patient's laboratory results during his first 5 days in the ICU

Values in red are above or below normal reference range for our laboratory. 
The patient was started on low-dose acetylsalicylic acid (ASA), corticosteroids (intravenous methylprednisolone 40 mg twice daily) and $2 \mathrm{~g} / \mathrm{kg}$ of intravenous immunoglobulin (IVIG) administered over 2 days. As toxic shock syndrome from bacterial sepsis could not be ruled out, piperacillin/tazobactam, vancomycin and clindamycin were also empirically started and blood, urine and bronchoalveolar lavage fluid samples were collected for microbiological culture.

The patient rapidly improved over the first 48 hours, so he was weaned from circulatory support, sedation was tapered and he was extubated after a total of 5 days of mechanical ventilation. The erythematous maculopapular skin rash initially mistaken as mottling quickly resolved (Fig. 3) Antibiotics were suspended after 7 days when all microbiological cultures were negative. A SARS-CoV-2 PCR test from a tracheal aspirate sample was negative 6 days after ICU admission. A second echocardiogram to reassess heart function, showed normal cavity sizes, preserved ejection fraction (63\%) and absence of mitral regurgitation and coronary aneurysms, hence allowing ASA to be stopped. However, repeat cardiac echocardiography 1 week later showed an aneurysmal dilation of the left main coronary artery, so ASA was restarted and a vitamin $\mathrm{K}$ antagonist added to the treatment regimen. Physical rehabilitation was intensified due to ICU-acquired myopathy.

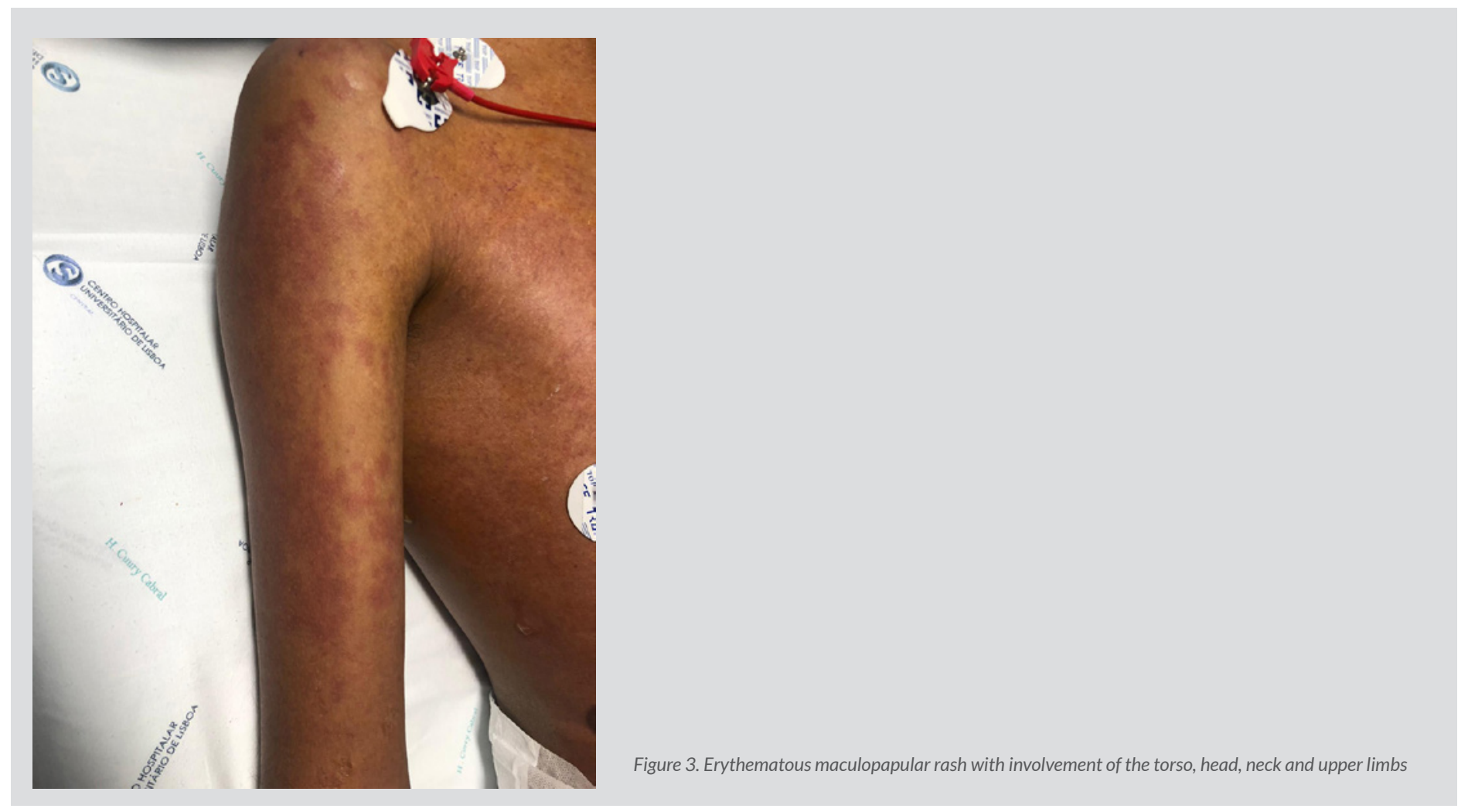

\section{DISCUSSION}

This case emphasizes how one of the most severe presentations of COVID-19 can easily be misdiagnosed, especially in young adults. As the presenting major symptom was abdominal pain, the case was initially interpreted as sepsis and managed by the surgical team accordingly. The typical presentation of MIS-C/PIMS-TS differs from that seen in other children with COVID-19 as it usually does not encompass previous medical conditions. Patients usually present with fever of sudden onset, diffuse rash, abdominal pain and/or nausea and vomiting. The majority of children with MIS-C/PIMS-TS did not have the respiratory symptoms typical of acute COVID-19 infection and already had IgG antibodies, suggesting that it might indeed be a post-infectious inflammatory syndrome. Our patient was SARS-CoV-2 negative by the time his clinical condition was improving. The recognition of this syndrome later in the pandemic might also be related to its rarity. Concerning heart malfunction, mild to moderate myocarditis can occur and present with decreased left ventricular contractility, which may be self-limited. Sequelae may only be evident later during follow-up.

Management of MIS-C/PIMS-TS, like the management of Kawasaki disease, is based on immunosuppressive therapy with corticosteroids and IVIG. Low-dose ASA is only recommended in the presence of coronary aneurisms, along with anticoagulation in select cases after expert consultation. Antiviral treatment with novel drugs such as remdesivir should be decided on a case-by-case basis and depends on local availability. Naturally, vasopressor and inotropic support with norepinephrine and dobutamine is essential for patients who present with cytokine storm associated with MIS-C/PIMS-TS. 


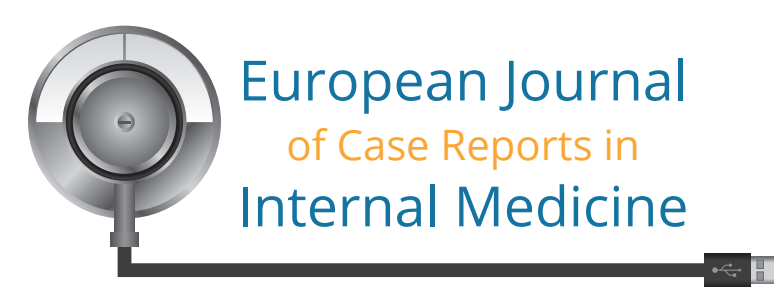

\section{CONCLUSION}

Physicians should be aware that teenagers and young adults are at risk of this condition. Thus, expert consultation with paediatric cardiologists is crucial, as PIMS-TS shares many features with Kawasaki disease and their experience in diagnosing, risk-stratifying and managing these cases is invaluable.

\section{REFERENCES}

1. Dong Y, Mo X, Hu Y, et al. Epidemiological characteristics of 2143 pediatric patients with 2019 coronavirus disease in China. Pediatrics 2020 ; doi: $10.1542 /$ peds.2020-0702.

2. Kim GB. Reality of Kawasaki disease epidemiology. Korean J Pediatr 2019;62(8):292-296.

3. De Graeff N, Groot N, Ozen S, Eleftheriou D, Avcin T, Bader-Meunier B, et al. European consensus-based recommendations for the diagnosis and treatment of Kawasaki disease - the SHARE initiative. Rheumatology (Oxford) 2019;58(4):672-682.

4. Loomba R, Villarreal E, Flores S. COVID-19 and Kawasaki syndrome: should we really be surprised? Cardiol Young 2020 May 15:1-2.

5. CDC Health Alert Network. Multisystem Inflammatory Syndrome in Children (MIS-C) Associated with Coronavirus Disease 2019. Available from: https://emergency.cdc.gov/ han/2020/han00432.asp

6. European Centre for Disease Prevention and Control. Paediatric inflammatory multisystem syndrome and SARS-CoV-2 infection in children - 15 May 2020. ECDC: Stockholm; 2020. Available from: https://www.ecdc.europa.eu/en/publications-data/paediatric-inflammatory-multisystem-syndrome-and-sars-cov-2-rapid-risk-assessment 